\title{
Prevalence of Amp C $\beta$-lactamase Producers Among Uropathogens at Shree Birendra Hospital.
}

\author{
Laxmi Dhungel ${ }^{1}$, Sarita Manandhar ${ }^{1}$, Sabita Bhatta ${ }^{2}$, Raina Chaudhary ${ }^{2}$. \\ ${ }^{1}$ Department of Microbiology, Trichandra Multiple College, Ghantaghar, Kathmandu; \\ ${ }^{2}$ Department of Microbiology, Shree Birendra Hospital, Chhauni, Kathmandu
}

\begin{abstract}
Introduction: Amp C $\beta$ lactamases confer resistance to a wide variety of $\beta$-lactam antibiotics and are poorly inhibited by $\beta$-lactamase inhibitors such as clavulanic acid. Plasmid carrying Amp $C$ enzyme also carry genes responsible of resistance to multiple other antibiotics, hence therapeutic options to infection caused by this type of organism is limited. Limited studies on prevalence of these organisms have been done in Nepal. The study is done to know the prevalence of Amp C $\beta$ lactamase producers among the uropathogens.
\end{abstract}

Methods: Amp C $\beta$ lactamase producers were detected by double disc synergy test using the disc of cefoxitin $(30 \mu \mathrm{g})$ and cefoxitn $(30 \mu \mathrm{g})$ plus phenylboronic acid $(20 \mu \mathrm{l})$. An increase in zone diameter of $\geq 5 \mathrm{~mm}$ to cefoxitin disc with phenylboronic acid versus cefoxitin alone was considered confirmed ABL producers.

Results: The ABL production was found in $8.94 \%$ of the total isolates. It was observed in $9.87 \%$ of $E$. coli isolates and in $20 \%$ of Ps. aeruginosa. ABL producers were found to be resistant to many drugs when compared to Non-ABL producers.

Conclusions: Amp C $\beta$ lactamase producers were found among uropathogens. They were resistant to many antibiotics compared to Non- Amp C $\beta$ lactamase producers.

KeyWords: amp C $\beta$-lactamase; uropathogens; Ps. Auruginosa.

\section{INTRODUCTION}

Amp C $\beta$ lactamases are class $\mathrm{C}$ or group I cephalosporinases capable to hydrolyze a wide variety of $\beta$-lactam antibiotics including alpha methoxy $\beta$-lactams such as cefoxitin, narrow and broad spectrum cephalosporins, aztreonam, and are poorly inhibited by $\beta$-lactamase inhibitors such as clavulanic acid ${ }^{1}$. They are one of the most common types of $\beta$-lactamase production $^{2}$. Dissemination of AmpC gene confined to the chromosome of various gram negative species on their plasmids has caused a substantial clinical threat. ABL producers are usually resistant to all the $\beta$-lactam antibiotics (except for cefepime, cefpirome and the carbapenems). However, they may appear susceptible to broad-spectrum cephalosporin and meet screening breakpoints for ESBLs on phenotypic confirmatory test when conventional CLSI guidelines are used. This may cause erroneous reporting leading to disastrous consequence when broad spectrum cephalosporins are used to treat serious infections ${ }^{3}$. They also carry genes that are responsible to resistances to multiple other antibiotics making therapeutic options limited ${ }^{4}$. There is no standard guideline for detection of Amp $\mathrm{C}$ production hence accurate prevalence remains unknown due to lack of testing. Limited study has been done on its occurrence in $\mathrm{Nepal}^{6}$. The study is done to know the prevalence of Amp C $\beta$ lactamase producers among the uropathogens.

Correspondence:

Laxmi Dhungel

Tri-Chandra Multiple College Ghantaghar,Kathmandu

Email:dhungel61@gmail.com 


\section{METHODS}

A descriptive cross-sectional study was conducted among patients suspected of UTI attending Birendra Hospital's microbiology laboratory, Chhauni, Kathmandu. The period for this research was March 14, 2013 to Sep 16, 2013. During the research work 1,544 midstream urine specimens were collected from patients clinically suspected of UTI. Semi quantitative method following quadrant streaking technique was used for enumeration and reporting as significant bacteriuria.

Pathogens were identified by standard methodology. The Cysteine lactose electrolyte deficient agar (CLED) medium was used for sample inoculation. Modified Kirby-Bauer disk diffusion method using Mueller Hinton Agar plate was used for antimicrobial susceptibility testing. There is no CLSI guideline for the detection of plasmid mediated AmpC $\beta$-lacamase (ABL) production ${ }^{4}$. In the present study cefoxitin disc $(30 \mu \mathrm{g})$ and an AmpC enzyme inhibitor, phenylborornic acid was used. Boronic acid has been reported as an effective inhibitor of class $\mathrm{C} \beta$ - lactamases; hence, inhibitor based method using it appears to be effective in discriminating this type of resistant isolate ${ }^{7}$. The isolates were used for screening of $\mathrm{ABL}$ production using cefoxitin disc. Those showing a zone of inhibition $<18 \mathrm{~mm}$ to cefoxitin $(30 \mu \mathrm{g})$ was considered as the screen positive for ABL production. The screen positive isolates were subjected to Double disc synergy test. The disc of cefoxitin $(30 \mu \mathrm{g})$ and cefoxitn $(30 \mu \mathrm{g})$ plus phenylboronic acid $(20 \mu \mathrm{l})$ was used. An increase in zone diameter of $\geq 5 \mathrm{~mm}$ to cefoxitin disc with phenylboronic acid versus cefoxitin alone was considered confirmed ABL producers ${ }^{8}$.

\section{RESULTS}

Significant growth was observed among $11.59 \%$ of the specimen. E. coli $(84.91 \%)$ was the predominant uropathogen. Ps. aeruginosa $(2.8 \%)$ and Morganellamorganii (2.8\%) were the second most common gram negative uropathogens. Enterococcus spp $(2.8 \%)$ was the major Gram positive uropathogen. The ABL production was found in $8.94 \%$ of the total isolates. It was observed in $9.87 \%$ of $E$. coli isolates and in $20 \%$ of Ps. aeruginosa (Table 1). ABL producers were found to be resistant to many drugs when compared to Non-ABL producers (Table 2).
Table1. Pattern of Bacterial Isolates Causing UTI and Amp C $\beta$ lactamase production

\begin{tabular}{|l|l|l|}
\hline Organism & $\begin{array}{l}\text { Isolates } \\
(\%)\end{array}$ & ABL (\%) \\
\hline E. coli $(152)$ & 84.91 & 9.87 \\
\hline Ps. aeruginosa(5) & 2.8 & 20 \\
\hline Morganellamorganii(5) & 2.8 & 0 \\
\hline Kl. Pneumonia (4) & 2.2 & 0 \\
\hline Enterobacter(4) & 1.1 & 0 \\
\hline Providenciarettgeri(2) & 1.1 & 0 \\
\hline Kl. Oxytoca(1) & 0.6 & 0 \\
\hline Cit. freundii(1) & 0.6 & 0 \\
\hline Acinetobacter(1) & 0.6 & 0 \\
\hline Enterococcus spp (5) & 2.8 & 0 \\
\hline Staph. Aureus(1) & 0.6 & 0 \\
\hline Total (179) & $100 \%$ & $8.94 \%$ \\
\hline
\end{tabular}

Table 2.Antibiotics Resistance (\%)

\begin{tabular}{|l|l|l|}
\hline Antibiotics & ABL producers & Non-ABL producers. \\
\hline Amoxycillin & 100 & 80 \\
\hline Ciprofloxacin & 87.5 & 51.55 \\
\hline Cephalexin & 100 & 78.43 \\
\hline Norfloxacin & 87.5 & 53.7 \\
\hline Nitrofurantoin & 25 & 9.93 \\
\hline Cotrimoxazole & 50 & 56.49 \\
\hline Gentamicin & 25 & 15.95 \\
\hline Ofloxacin & 87.5 & 51.27 \\
\hline Cefotaxime & 100 & 39.62 \\
\hline Cefoxitin & 100 & 21.47 \\
\hline
\end{tabular}

\section{DISCUSSION}

Higher resistance to $\beta$-lactam and multiple other antibiotics has made Amp C $\beta$ lactamase a worldwide concern. As many physicians and clinical laboratories are unaware of this type of organism, they have remained undetected and responsible for several nosocomial outbreak ${ }^{1}$.

The ABL production was found in $8.94 \%$ of isolates. E. coli $(9.87 \%)$ and $P$ s. aeruginosa $(20 \%)$ were ABL producers. The result was in harmony with Singhalet $a l .{ }^{9}$ and Sasirekha and Shivakumar ${ }^{10}$. However the result was in contrast with Tan et al. ${ }^{11}$ who found ABL production in $26 \%$ of study isolates. This difference may be due to the variation in ability to produce Amp C $\beta$ 
lactamase in different Gram negative bacteria, different clinical specimens and difference in selection criteria of the isolates ${ }^{10}$. The study was unable to distinguish between plasmid mediated and chromosomal Amp C enzyme.

ABL producers were found to be more resistance to cephalosporins compared to Non-ABL producers. Dalelaet al. ${ }^{12}$ also observed similar result. Higher rate of resistance was shown by majority of ABL producer to commonly used antibiotic such as fluoroquinolones, gentamicin and nitrofurantoin. However, the difference in resistance among $\mathrm{ABL}$ producers and Non- Abl producers were statistically insignificant.Conjugative dissemination of AmpC $\beta$-lactamase encoding plasmids is thought to facilitate the spread of resistance against a wide range of antibiotics among different members of Enterobacteriaceae causing AmpC $\beta$-lactamase production frequently accompanied by multidrug resistance ${ }^{1}$. This high rate of resistance shown to commonly used antibiotic is a worrisome as these drugs are cheaper and are easily available in different pharmacy counters across Nepal. This makes therapeutic options to be limited against these pathogens as they are resistant to multiple commonly used antimicrobial agents ${ }^{6}$.

\section{CONCLUSIONS}

Amp C $\beta$ lactamase producers were resistant to many antibiotics. Its regular surveillance is required for establishment of proper antimicrobial treatment strategy and policy making due to $\mathrm{ABL}$ positive infections.

\section{REFERENCES}

1. Mohamudha PR, Harish BN, Parija SC. Amp C $\beta$ lactamases among Gram negative clinical isolates from a tertiary hospital, South India. Brazilian Journal of Microbiology. 2010;41(3):596-602. $\quad$ http://dx.doi.org/10.1590/S1517$\underline{83822010000300009}$.

2. Coudron PE, Moland ES, Thomson KS. Occurrence and detection of AmpC $\beta$-lactamases among Escherichia coli, Klebsiellapneumoniae, and Proteus mirabilis isolates at a veterans medical center. J ClinMicrobiol. 2000;38:1791-6.

3. Doi Y, Paterson DL. Detection of plasmid-mediated class C b-lactamases. Int. J. of Inf. Diseases. 2007;11:191-197i. http://dx.doi.org/10.1016/j.ijid.2006.07.008.

4. Jacoby GA. AmpC $\beta$-lactamses. Clin. Microbiology Reviews 2009;22(1):161-82. http://dx.doi.org/10.1128/CMR.00036$\underline{08}$.

5. Thomson KS. Extended-Spectrum- $\beta$-Lactamase, AmpC, and Carbapenemase Issues. J ClinMicrobiol. 2010;48(4):10191025. http://dx.doi.org/10.1128/JCM.00219-10

6. Baral P, Neupane S, Marasini BP, Ghimire KR, Lekhak B, Shrestha B. High prevalence of multidrug resistance in bacterial uropathogens from Kathmandu, Nepal. BMC Res Notes. 2013;19(5):38.

7. Hemalatha V, Padma M, Sekar U, Vinodh TM and ArunkumarAS.Detection of Amp C $\beta$ lactamase producing Escherichia Coli and Klebsiella by an inhibitor based method. Ind. J. med. research. 2007;126:220-3.

8. Song W, Jeong SK, Kima JS, Kima HS, Shina DH, Rohc $\mathrm{KH}$, Lee KM. Use of boronic acid disk methods to detect the combined expression of plasmid-mediated AmpC $\beta$-lactamases and extended-spectrum $\beta$-lactamases in clinical isolates of Klebsiella spp., Salmonella spp., and Proteus mirabilis. Diagnostic Microbiology and Infectious Disease. 2007; 57:315-8. http://dx.doi.org/10.1016/j. diagmicrobio.2006.08.023 